\section{O MITO DA VERDADE REAL: O PAPEL DA MÍDIA NA CONSTITUIÇÃO DA MEMÓRIA COLETIVA EM DETRIMENTO DA ACESSIBILIDADE JUDICIÁRIA}

\section{THE REAL TRUTH MYTH: THE MEDIA'S FUNCTION IN THE FORMATION OF COLLECTIVE MEMORY ON JUDICIAL'S ACCESSIBILITY PREJUDICE}

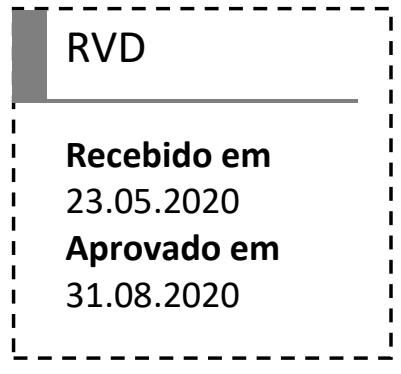

Evelyn Oliveira Viana ${ }^{1}$ Sheila Marta Carregosa Rocha ${ }^{2}$

\title{
RESUMO
}

A Constituição da República de 1988 consagrou após anos de repressão o reconhecimento legal dos princípios tais como a dignidade da pessoa humana e dos direitos fundamentais, sendo alguns deles: o direito à informação, à memória e ao acesso à justiça, dessa forma, no Brasil passa vigorar o denominado Estado Democrático de Direito. Nesse sentido, é possível ressaltar que a sociedade pós-moderna possui um contexto de proteção aos seus direitos assegurados por lei. Todavia, este momento social traz consigo um exacerbado poder midiático no que tange ao oferecimento de informações e construção de opiniões, moldando assim, o sujeito em todos os aspectos. Este artigo, utilizando-se do método indutivo, baseando-se na pesquisa bibliográfica, tem como objetivo demonstrar como ocorre esse poder da grande mídia na construção da memória e de que forma prejudica a construção crítica do indivíduo de modo

1 Pós-graduanda em Direito de Família e Sucessões; Graduada em Direito pela Universidade do Estado da Bahia. E-mail evelyn.oliveiraviana@gmail.com ORCID: https://orcid.org/0000-0002-2873-7798 Endereço: Rua Pompílio P Moura Ribeiro, № 158, Bairro: Centro, Brumado, Bahia, Brasil - CEP: 46100 000.

2 Doutora em Família na Sociedade Contemporânea. Mestre em Família na Sociedade Contemporânea. Especialista em Direito Civil. Especialista em Metodologia do Ensino Superior com Ênfase em Novas Tecnologias. Especialista em Psicopedagogia. Bacharela em Direito. Licenciada em Letras Vernáculas. Pesquisadora do Núcleo de Estudos sobre Governação e Instituições e do Núcleo de Estudos em Direitos Humanos da Pós Graduação stricto sensu da Universidade Católica do Salvador. Pesquisadora do Grupo de Pesquisa em "Educação Direitos humanos e Fronteira" da Universidade Federal do PAMPA. Docente da Universidade do Estado da Bahia (UNEB) do Departamento de Ciências Humanas do Campus XX - Brumado. Lider do Grupo Direitos Humanos, Envelhecimento e Violências, certificado pela UNEB e inscrito no Diretório dos grupos de Pesquisa do CNPq, DHEV/UNEB/Cnpq dgp.cnpq.br/dgp/espelhogrupo/1551266856460047. E-mail sheila.carregosa@gmail.com ORCID:https://orcid.org/0000-0003-2964-3707. 
a violar direitos como: do acesso à justiça e à memória em nome do direito à informação e como consequência, a insegurança jurídica ao estado Democrático de Direito.

PALAVRAS-CHAVE: Poder da mídia; Direito à informação; Acesso à justiça; Direito à Memória; Estado Democrático de Direito.

\begin{abstract}
In Brazil, after years of repression, the legal recognition of principles such as the dignity of the human person and fundamental rights was recognized, including: the right to information,memory and access to justice with the Federal Constitution of 1988, entering into force the Democratic State of Law. In this sense, it has been that postmodern society lives in a context of protection of rights, however, it has brought an exacerbated media power in relation to the offering of information, shaping the subject in all aspects. This work aims at using the inductive method and based on bibliographical research to demonstrate how this power of the media is given in the construction of memory and how this damages the construction of acritical individual, thus violating access to justice and To the memory in the name of the right to information and as a consequence, legal insecurity to the Democratic State of Law.
\end{abstract}

KEYWORDS: Media Power; Right to information; Access to justice; Memory; Democratic State of Law.

\title{
1. INTRODUÇÃO
}

A Constituição da República Federativa do Brasil de 1988 faz parte do rol de Cartas Magnas a inserir, de forma expressa, os direitos fundamentais e colocá-los como cláusula pétrea. Desse modo, tem-se a mudança de entendimento sobre como o Direito deve ser no aspecto formal, no qual admite-se defesa ampla para evitar que novas barbáries sejam cometidas "em nome da lei", denominando-se Estado Democrático de Direito.

Contudo, o desenvolvimento tecnológico da era pós-moderna trouxe consigo a liquidez das relações, o acesso praticamente em tempo real, bem como o modo que uma informação é captada e repassada. Assim, apesar, das normas constitucionais garantirem a memória, a identidade e o acesso à justiça, como direitos natos e 
essenciais ao ser humano, é possível questionar a validade da aplicabilidade destes, uma vez que os meios de comunicação em massa estão pautados nos interesses de uma classe hegemônica a qual influência de forma eminentemente sutil e imperceptível.

Nesse sentido, observa-se que ao passo dos inúmeros benefícios trazidos pela grande quantidade de informações, estas também tornam-se hábeis instrumentos para manipulação da realidade, pois a sua deturpação faz com que a alienação e desfiguração dos elementos nacionais aptos a consolidar os elementos constitutivos de um indivíduo, tais como: a ideia de identidade e de pertencimento a um grupo acabem sendo moldados pela grande propulsora da informação - a mídia. Dessa forma, ao manipular a construção identitária do indivíduo, os meios de comunicação em massa, não só viola o direito à informação, mas também outros, como o da preservação da memória, bem como o conceito constitucional de direito à vida digna.

Em vista disso, o que se tem é uma relativização dos direitos fundamentais a partir da ideia de parcialidade dos meios de comunicação, vez que o compromisso com a verdade empregada na divulgação das informações, esbarra na ideologia do custo benefício tornando-se um dos principais instrumentos para o atual período conflituoso dentro do País. Dessa forma, resta prejudicada as relações, pois torna quase vital o seguimento padronizado de um comportamento imposto pela sociedade aqui também denominada de sociedade do espetáculo.

Nesse sentido, é possível observar o prejuízo que a influência midiática causa também na esfera jurídica ao transmitir determinados comentários e programas, os quais além de violar garantias e direitos assegurados constitucionalmente, acabam por interferir no acesso à justiça ao permitir a criação ou deturpação de conceitos legais impelindo à sociedade a manter-se longe dos aparatos judiciais.

\section{A CONCEPÇÃO HITÓRICA DE VERDADE E O PAPEL DOS DIREITOS FUNDAMENTAIS: O SURGIMENTO DA ERA DA INFORMAÇÃO}

A verdade é uma busca infinita da humanidade, sendo confundida muitas vezes com: cultura, dogmas, preceitos éticos e morais uma vez que estes são. capazes de 
conduzir a um lapso de veracidade que subverta toda série de questionamentos e dúvidas. No entanto, todos esses aparatos, ao mesmo tempo em que cria determinados padrões a serem seguidos,camuflam e transmutam toda e qualquer outra perspectiva de acesso a determinadas partes da informação.

Outra face da verdade pode ser identificada como a ideologia, um mecanismo etéreo, abstrato, imaterial, mas presente em todos os detalhes da sociedade desde a antiguidade até o limiar da era capitalista pós-moderna. A partir daí, tormou-se vital a criação de regras e acordos os quais visassem o convívio e possuíssem uma diretriz básica de respeito. Assim, surgem também, as instituições que cuidam dessa organização social, símbolos capazes de manter a coletividade integrada, como o Estado, conceitos de padrão moral e um conjunto de regras que nortearão toda uma forma de pensar e ver o mundo, a saber, o Direito. Pierre Bourdieu afirma que:

Os - sistemas simbólicos- como instrumentos de conhecimento e de comunicação, só podem exercer um poder estruturante porque são estruturados. O poder simbólico é um poder de construção da realidade que tende a estabelecer uma ordem gnoseológica: sentido imediato do mundo, em particular, do mundo social, coadunando com aquilo que Durkheim chama 'o conformismo lógico', quer dizer, uma concepção homogênea do tempo, do espaço, do número, da causa, que torna possível a concordância entre as inteligências. (BOURDIEU, p.9, 2007)

Nesse sentido, pode-se dizer que a partir do convívio social, nasceu a ideia de direitos e deveres, bem como do que seja justiça, todavia, esta foi sendo estruturada de várias formas com o passar do tempo, desde a criação da Lei de Talião, resumida na celebre frase "do olho por olho e dente por dente" até a ideia atual da análise de cada caso concreto .

As modificações que vemos, hoje, na interpretação do Direito vieram após os horrores da segunda grande guerra em que genocídios foram fundamentados na legalidade e em normas. Com a instituição do Estado Constitucional de Direito, observa-se que o intuito era prevenir que o Direito não funcionasse novamente como 
arma de destruição e de injustiças ampliando a visão de Kelsen da subsunção do fato a norma. Nas palavras de Noberto Bobbio:

Os direitos do homem, por mais fundamentais que sejam, são direitos históricos, ou seja, nascidos em certas circunstâncias, caracterizados por lutas em defesa de novas liberdades contra velhos poderes, e nascidos de modo gradual, não todos de uma vez e nem de uma vez por todas. ( BOBBIO, 1992, p.5)

Desse modo, a evolução deste, no formato como hoje é conhecido, distancia-se das peculiares concepções legalistas do Direito Puro, alocando-se no espaço-tempo ao qual chamamos de 'pós-positivismo', tendo como marca a era das Constituições Fundamentais cuja concepção filosófica baseia-se na valorização do ser humano em sua dignidade, bem como, dos direitos humanos: direito à vida, direito à liberdade, direito à informação, ao acesso à justiça, entre outros, nascendo assim, os direitos fundamentais. De acordo com Lênio Luiz Streck:

É nesse sentido que a supremacia da Constituição democrática impede, como garantia dos direitos fundamentais, qualquer alteração que descumpra as normas nela previstas para reger uma reforma constitucional (STRECK, 2014, p.267).

Assim como o Direito, a sociedade também foi evoluindo, tais quais as suas necessidades de conhecimento e expansão, desta forma, houve um desenvolvimento dos mecanismos de comunicação e interação de modo a facilitar o compartilhamento de informações e experiências. Nos dias atuais, esse se dá em grande escala e de forma instantânea, podendo chamar esta geração de a era da informação. Desse modo afirma Debord:

É pelo princípio do fetichismo da mercadoria, a sociedade sendo dominada por «coisas supra- sensíveis embora sensíveis», que o espetáculo se realiza absolutamente. O mundo sensível é substituído por uma seleção de imagens que existem acima dele, ao mesmo tempo em que se faz reconhecer como o sensível por excelência. $O$ mundo ao mesmo tempo presente e ausente que o espetáculo 
apresenta é o mundo da mercadoria dominando tudo o que é vivido. $O$ mundo da mercadoria é mostrado como ele é, com seu movimento idêntico ao afastamento dos homens entre si, diante de seu produto global (DEBORD, p.29, 2003).

Impetrada pela indústria cultural em um primeiro momento, aos consumidores de mercadoria, agora, as informações adaptam-se para além do público alvo fabril e, sem discriminação de escolaridade, condição financeira ou nacionalidade, são parte de uma mesma massa que é dominada pela falsa noção de verdade, fruto de uma seleção precária da informação.

Nesse sentido, o acesso à informação escorreita em uma sociedade tão desigual, é de certa forma, possibilitar ascensão social. Na era do espetáculo, das propagandas, do lúdico e da indústria cultural, a informação passou a ser um artigo valioso na pós-modernidade. Tal situação não se dá pela falta dessas, mas sim pela escassez das que possuam compromisso com a verdade factual. Nas palavras de Guy Debord:

Neste movimento essencial do espetáculo - que consiste em ingerir tudo o que existe na atividade humana em estado fluido para depois vomitá-lo em estado coagulado, para que as coisas assumam seu valor exclusivamente pela formulação em negativo do valor vivido - nós reconhecemos a nossa velha inimiga que embora pareça trivial à primeira vista é intensamente complexa echeia de sutilezas metafísicas a mercadoria (DEBORD , 2003, p. 28).

Dessa forma, o domínio da verdade, ou melhor, a detenção das verdades lança uma ofensiva agressiva contra a sociedade de tal modo que os sujeitos se veem dependentes com suas emoções e percepções intensamente interligadas aos aparatos de comunicação. Nesse sentindo, tanto a informação quanto os meios de comunicação, tornaram-se dispositivos mercantis cujo propósito é o de estabelecer uma condição de controle, na qual a verdade é cedida de forma controlada e as ideologias concebidas de forma intencionada. Guy Debord afirma que: 
A ideologia é a base do pensamento duma sociedade de classes, no curso conflitual da história. Os fatos ideológicos não foram nunca simples quimeras, mas a consciência deformada das realidades, e, enquanto tais, fatores reais exercendo, por sua vez, uma real ação deformada; na medida em que a materialização da ideologia na forma do espetáculo, que arrasta consigo o êxito concreto da produção econômica autonomizada, se confunde com a realidade social, essa ideologia que pode talhar todo o real segundo o seu modelo (DEBORD, 2003, p. 160).

Assim, o modo como o poder da informação e, por consequência da construção de um indivíduo perpassa, primeiramente, pela modelagem midiática, retira do cidadão a oportunidade de análise completa das situações ao seu redor prejudicando outras esferas de direitos que lhes são garantidos, visto que como pensar o acesso à justiça antes de pensar o acesso à informação? Sendo esta elemento axial do poder dominante dentro do sistema capitalista, seja pela indução ao consumo, seja pela perpetuação de ideologias, como podem as massas subverterem a esta condição sem o acesso democrático à justiça ou uma noção imparcial do direito? Tais questionamentos trazem à baila o controle superestrutural que pode ser identificado nos mais variados seguimentos de organização social e estatal da atualidade.

Quando a ideologia, que é a vontade abstrata do universal, e a sua ilusão, se legitima pela abstração universal e pela ditadura efetiva da ilusão na sociedade moderna, ela já não é a luta voluntarista do parcelar, mas o seu triunfo. Daí a pretensão ideológica adquire uma espécie de fastidiosa exatidão positivista: ela já não é uma escolha histórica, mas uma evidência. Numa tal afirmação, os nomes particulares das ideologias desvanecem-se. Mesmo a parte operante propriamente ideológica ao serviço do sistema já não se concebe senão enquanto uma «base epistemológica» que se pretende além de qualquer fenômeno ideológico. A própria ideologia materializada não tem nome, da mesma forma que não tem qualquer programa histórico enunciável. Ou seja, a história das ideologias inexiste (DEBORD, 2003, p.160-1).

Assim há uma íntima relação entre mídia e justiça, nas quais decisões judiciais são proferidas sob pressão popular exercida pela articulação midiática; a forma como 
alguns programas de auditório em sua total formatação - sensacionalistas - destratam perturbações sociais relegando ao sujeito, deixando-o exposto a um conjunto de julgamentos e ao chamado "linchamento virtual". A esse cidadão exposto no circo da TV ou das Redes Digitais não Ihe resta muito, pois o próprio Estado já o enxerga como inimigo, bem como a verdade dos fatos não vai além do estereótipo "bandido bom é bandido morto", alheio a questão de que se trata de indivíduo protegido pelas leis pátrias e, portanto, possuidor de direitos.

\section{O "ABSOLUTISMO" DO DIREITO À INFORMAÇÃO NA SOCIEDADE PÓS- MODERNA EM DETRIMENTO À CONSTRUÇÃO DA MEMÓRIA E AOS DIREITOS FUNDAMENTAIS}

O conceito de memória pode ser compreendido a partir da informação. Destarte, após anos de repressão, este assim como aquele são, hoje, direitos fundamentais garantidos em nossa Lei Maior de 1988, sendo defeso qualquer tipo de vedação ou restrição. Desse modo aduz Paulo Lopo Saraiva:

A Constituição proíbe qualquer restrição ou qualquer embaraço ao direito de informação, erigindo esta condição como uma das prerrogativas do Estado Democrático de Direito. De outro bordo, veda qualquer tipo de censura ideológica, política e artística (SARAIVA, 2006, p. 27).

Nesse sentido, é possível analisar que para a construção de um direito à memória efetivo é preciso ter acesso à informação. Todavia, na sociedade pós-moderna este se dá de forma rápida e instantânea de modo que vários discursos são transmitidos, mas apenas alguns são repetidos e reproduzidos para serem repassados as demais gerações.

Partindo dessa ideia de construção individual e também social, é que o conceito de memória pode ser confundido com o de identidade, o que não estaria errado, uma vez que para a estruturação desta é necessário reconhecer-se dentro de um espaço, de 
um povo, compartilhando as suas histórias. Dessa forma, nas palavras de Joel Candau: "A memória é, de fato, uma força de identidade" (CANDAU, 2011, p. 17).

Assim sendo, a memória individual perpassa pela construção da identidade não só de um indivíduo, mas também de um grupo, a qual é denominada de identidade coletiva. Esta pode ser entendida como representações baseadas na similitude, uma espécie de sentimento de pertencimento a um grupo social, pautada nas memórias de origem, história e natureza do grupo. Conforme Maurice Halbwachs:

[...] se pode falar em memória coletiva quando evocamos um fato que tivesse um lugar na vida de nosso grupo e que víamos, que vemos ainda agora no momento em que recordamos, do ponto de vista desse grupo" (HALBWACHS, 2003, p.41).

Diante disso, é possível visualizar que o poder simbólico da grande mídia atua de forma a incitar no indivíduo a "cultura da memória curta" e da falta de capacidade crítica, transformando a verdade em conceitos parciais e valores ideológicos sem o devido embasamento para sustentar a sua formação enquanto indivíduo ativo dentro da sociedade, servindo apenas para manter a ordem social desigual. Assim, o direito à memória é corrompido desde o seu nascimento, posto que a informação, as ideologias passadas não representam uma coletividade, restando apenas a ilusão de discursos vazios reproduzidos massivamente. Assim, aduz Pierre Bourdieu:

[...] as relações de comunicação são, de modo inseparável, sempre relações de poder que dependem, na forma e no conteúdo, do poder material ou simbólico acumulado pelos agentes (ou pelas instituições) envolvidos [...]. É enquanto instrumentos estruturados e estruturantes de comunicação e de conhecimento que os sistemas simbólicos cumprem sua função política de instrumentos de imposição ou de legitimação da dominação, que contribuem para assegurar a dominação de uma classe sobre outra [...]. (BOURDIER, 2007, p.11)

A partir dessa análise é possível perceber que faz parte do conceito de memória a identificação de símbolos como sendo aqueles os quais constituem o seu modo de compreender os fatos diários. Assim, pode-se dizer que os meios de comunicação exercem este simbolismo de forma quase imperceptível. O superficial, o instantâneo, a 
falsa percepção de existência e a fantástica transformação da realidade modifica a verdade, a cultura, os costumes e, por conseguinte, a memória e as demais formas de relação entre os indivíduos em um turbilhão de dúvidas nas quais levam em direção ao individualismo abrindo espaço para dominadores e dominados - a lógica do consumo como forma de inserção social e percepção da realidade.

Nessa lógica, a indústria cultural trazida à tona pela Escola de Frankfurt ou a Sociedade do Espetáculo proposta por Debord denunciam o vazio oblíquo no qual a sociedade ocidental se lançou sem grandes defesas. Além de muitos teóricos, como Adorno e Horkheimer, os quais analisaram a capacidade que o capital, através de suas múltiplas faces, possui de controlar as massas numa opaca epifania a qual aliena e esvazia as percepções sociais subvertendo, desta forma, a natureza coletiva do ser humano. Aduz Debord:

A ideologia é a base do pensamento duma sociedade de classes, no curso conflitual da história. Os fatos ideológicos não foram nunca simples quimeras, mas a consciência deformada das realidades, e, enquanto tais, fatores reais exercendo, por sua vez, uma real ação deformada; na medida em que a materialização da ideologia na forma do espetáculo, que arrasta consigo o êxito concreto da produção econômica autonomizada, se confunde com a realidade social, essa ideologia que pode talhar todo o real segundo o seu modelo (DEBORD, p.160, 2003).

Ainda dentro do contexto social pós-moderno, as informações possuem um grande propulsor, a grande mídia, responsável pela veiculação da maiora destas, tornou-se um dos poderes, senão o maior deles e através de seu discurso nasce uma criação de patrões, consenso, ou simplesmente o senso comum. Além disso, esse acesso, praticamente instantâneo, permite a interferência direta em direitos tais como: o de privacidade e imagem, visto que em grande parte dos casos, não ocorre uma filtragem daquilo que é verdade, verossimilhante, ou apenas uma maneira de propagar aquilo que é mais lucrável. Nesse sentido tem-se as palavras de Schreiber: 
Os extraordinários benefícios trazidos por esta genuína "revolução" talvez só sejam comparáveis, em magnitude, aos riscos que derivam de todo este novo instrumental tecnológico e da exploração ainda incontrolada destas novas fronteiras (SCHREIBER, 2013, p. 12).

Dessa forma, em nome do direito à informação são feitas violações a direitos e princípios também considerados como fundamentais, tais como: o direito à memória, 0 acesso à justiça e por consequência, ao princípio da dignidade da pessoa humana. Nesse sentido, tem-se os ensinamentos de Ingo Wolfgang Sarlet:

[...] a noção de dignidade repousa ainda que não de forma exclusiva [...] na autonomia pessoal, isto é, na liberdade (no sentido de capacidade para a liberdade) - que o ser humano possui de, ao menos potencialmente, formatar a sua própria existência e ser, portanto, sujeito de direitos, já não mais se questiona que a liberdade e os direitos fundamentais inerentes à sua proteção constituem simultaneamente pressuposto e concretização direta da dignidade da pessoa [...] (SARLET, 2007, p.87).

Nesse sentido, o direito à informação passou a ganhar, de forma sutil, uma força maior dentro do Direito, uma vez que princípios como o da presunção de inocência, em casos de grande repercussão, tais como: caso "Isabella Nardoni”, Caso "Eloá", garantias do acesso à justiça efetivo do réu/indiciado sejam completamente esquecidos. Ainda baseado no forte apelo midiático e tendo a comoção popular como consequência, teve-se a inclusão do crime de homicídio qualificado integrando o rol dos crimes hediondos após o caso conhecido como "Caso Daniela" - filha da autora Gloria Perz. Assim nos ensinamentos de Schreiber:

[...] ignorar os riscos trazidos por toda essa imensa transformação dos meios de comunicação. Superexposição dos indivíduos, violações à privacidade, uso indevido de imagem, venda de objetos pessoais, furto de identidade são apenas alguns dos riscos trazidos pelas novas tecnologias de comunicações, além de outros que dizem respeito ao 
próprio papel da Mídia em sociedades democráticas (SCHREIBER, 2013, p. 12).

Deve-se levar em consideração, contudo, que nenhum direito fundamental é absoluto, ou seja, quando em colisão com outros em casos concretos, prevalecerá sempre, uma vez que para a garantia e respeito dos valores jurídicos como a ordem, a segurança, a liberdade e a justiça torna-se necessário a análise de cada caso concreto, para que não ocorra a marginalização do princípio da dignidade da pessoa humana.

Porém, o que acaba ocorrendo é uma relativização dos demais direitos quando em confronto com o direito à informação, pois ao se bloquear determinada 'notícia', automaticamente é utilizada a vedação constitucional à censura. Assim, conquanto a informação seja vital para que se possa construir opiniões e por consequência a identidade do indivíduo, bem como a da sua memória coletiva, não se pode deixar de aplicar os princípios da razoabilidade e da proporção, visto que estes também são garantias constitucionais.

Além disso, é preciso também salientar o fato de que as informações devem ser analisadas de forma a entender qual a sua mensagem real, visto que o mito da neutralidade interpretado como princípio da imparcialidade judicial, não é aplicado de forma eficiente no judiciário, ou pelos meios de comunicação, nesta lógica é possível observar como foi veiculada a tramitação do processo de impeachment da expresidenta Dilma Rousseff transmitida pela rede Globo de Televisão. Nesse sentido, tem-se as palavras de Paulo Bonavides:

Com efeito, trata-se aqui da mídia - esta, sim, a caixa preta da democracia, que precisa de ser aberta e examinada para percebermos quantos instrumentos ocultos, sob o pálio legitimamente de expressão, lá se colocam e utilizam para degradar a vontade popular, subtrair-lhe a eficácia de seu título de soberania, coagir a sociedade e o povo, inocular venenos sutis na consciência do cidadão, construir falsas lideranças com propaganda enganosa e ambígua, reprimir e sabotar com a indiferença e o silêncio dos meios de divulgação, tornados, inacessíveis, a voz dos dissidentes e seu diálogo com a sociedade, manipular, sem limites e sem escrúpulos, a informação, numa aliança com o poder que 
transcende as raias da ética e tolher, enfim, a criação de uma opinião pública, livre e legítima (BONAVIDES, 2001, p. 64).

Portanto, é preciso analisar o direito à informação como fundamental. Porém, deve-se observar a fonte na qual foi veiculada, como foi transmitida, bem como o contexto no qual é inserida, levando-se em consideração que para a obtenção de uma vida digna tal como preleciona a Constituição, é necessário, primeiramente, ser um indivíduo com capacidade de discernir qual o seu papel social para que outros não o façam.

\section{O PODER DA MÍDIA NA SOCIEDADE PÓS-MODERNA: A RELATIZAÇÃO DO ESTADO DEMOCRÁTICO DE DIREITO E O ESPETÁCULO DO ACESSO À JUSTIÇA}

Dentro da sociedade pós-moderna uma de suas principais características é o acesso rápido às notícias, todavia, este grande volume de informações transmitidas a um só tempo, em conjunto com a falta de costume desta geração em conferir as fontes tem-se como resultado a propagação de falsas informações, ou simplemente fake news. De acordo com Zygmunt Bauman:

Acesso a "informação" (em sua maioria eletrônica) se tornou o direito humano mais zelosamente defendido e o aumento do bem-estar da população como um todo é hoje medido, entre outras coisas, pelo numero de domicílios equipados com (invadidos por?) aparelhos de televisão. E aquilo sobre o que a informação mai iforma é a fluidez do mundo habitado e a flexibilidade dos habitantes. [...] a perecibilidade dos noticiários enquanto informação sobre o "mundo real" é em si mesma uma importante informação: a transmissão das noticias é a celebração constante e diariamente repetida da enorme velocidade da mudança, do acelerado envelhecimento e da perpetuidade dos novos começos (2001, p. 195).

Dessa forma, traços da identidade como a cultura, as quais deveriam ser percebidas e assimiladas de modo a parecerem escolhas individuais acabam tornando- 
se, meras relações de consumo e necessidades ditadas por determinados grupos que almejam conquistar as classes com o fim de mantê-las cativas e sob fácil domínio. Assim aduz Zygmunt Bauman:

Esta nossa sociedade é uma sociedade de consumidores. E, como o resto do mundo visto e vivido pelos consumidores, a cultura também se transforma num armazém de produtos destinados ao consumo, cada qual concorrendo com os outros para conquistar a atenção inconstante/errante dos potenciais consumidores, na esperança de atraíla e conservá-la por pouco mais de um breve segundo (BAUMAN, 2010, pp. 33-34).

Ao fazer uma análise mais aprofundada, é possível perceber que em sua essência, o ter foi substituído pelo ser, as relações interpessoais foram substituídas pela tela do celular e as fontes já não são buscadas com afinco. Assim aduz Feuerbach:

Nosso tempo, sem dúvida...prefere a imagem a coisa, a cópia ao original, a representação à realidade, a aparência ao ser... O que é sagrado para ele, não passa de ilusão, pois a verdade está no profano. Ou seja, à medida que decresce a verdade a ilusão aumenta, e o sagrado cresce a seus olhos de forma que o cúmulo da ilusão é também o cúmulo do sagrado (FEUERBACH, 2009, p.6).

Já Guy Debord define essa situação como - A Sociedade do Espetáculo - que também rendera um livro com mesmo título. Nesta obra, o autor debate a situação vazia na qual o indivíduo se coloca diante das incursões que a conjuntura cultural capitalista Ihe impõe. Dessa forma, tem-se uma metamorfose do feitichismo denunciado por Marx em uma realidade na qual o homem é a própria mercadoria e esta assume a relevância inerente aos homens.

Nessa lógica, um dos agentes principais de provimento desta maneira de pensar e agir é a grande mídia. Por meio de uma programação voltada a selecionar o conteúdo a partir do viés que melhor aumentar os números do ibope e também atendam ao interesse do capital, isto é, daqueles que comandam o cartel midiático brasileiro, a verdade passa a ser uma questão de ponto de vista, assim como a ideia de 
construção de memória e do acesso à justiça. Assim têm-se as palavras de Michel Foucault:

Em nossas sociedades, "a economia política" da verdade tem cinco características historicamente importantes: a "verdade" é centrada na forma de discurso científico e nas instituições que o produzem; está submetida a uma constante incitação econômica e política (necessidade de verdade tanto para a produção econômica, quanto para o poder político); é objeto, de várias formas, de uma imensa difusão e de um imenso consumo (circula nos aparelhos de educação ou de informação, cuja extensão no corpo social é relativamente grande, não obstante algumas limitações rigorosas); é produzida e transmitida sob o controle, não exclusivo, mas dominante, de alguns grandes aparelhos políticos ou econômicos... meios de comunicação (FOUCAULT, 2003, p.13).

Desse modo, embora o século seja o $X X I$, a razão para se transmitir determinada informação decorre dos impactos econômicos que esta gerará. Por isso, o poder de contar a história continua sendo o mesmo do passado, a saber, da classe dominante. Da mesma forma, analisando-se as mudanças que esta época causou no contexto jurídico, uma das principais áreas de relação entre pessoas, é possível perceber uma alteração da atuação do Poder Judiciário de forma que deturba o denominado Estado Democrático de Direito. Nas palavras de Dirley da Cunha Júnior:

Efetivamente, o Estado Democrático de Direito é princípio fundamental que reúne os princípios de Estado de Direito e do Estado Democrático, não como simples reunião formal de seus respectivos elementos, tendo em vista que revela um conceito novo que os supera, mas como providência de transformação do status quo e garantia de uma sociedade pluralista, livre, justa e solidária, em que todo poder emane do povo e seja exercido em benefício do povo, com reconhecimento e a afirmação dos direitos humanos fundamentais que possam realizar, na sua plenitude, a dignidade da pessoa humana (JÚNIOR, 2016, p.462).

Nessa fase atual de compreensão dos aparatos legais, o parâmetro para inclusão de leis, em aspectos formais e materiais devem estar em consonância com o texto constitucional, vez que esta é a norma suprema do ordenamento jurídico. Além 
disso, reconhece-se a força normativa dos princípios, tendo como alicerce o princípio da dignidade da pessoa humana. Desse modo, afirma Dirley da Cunha Júnior:

[...] destaca-se, nesse contexto, como uma teoria jurídica a justificar a mudança de paradigma [...] em face do reconhecimento da força normativa da Constituição, com eficácia jurídica vinculante e obrigatória, dotada de supremacia material e intensa carga valorativa (JÚNIOR, 2016, p. 45).

Assim sendo, pode-se observar que esta soberania constitucional divide espaço com um novo poder moderador: os meios de comunicação, pois na presente conjuntura social produz-se conteúdo capaz de informar, mas ao mesmo tempo reduz o indivíduo a mero expectador de seus direitos e garantias. A exemplo disso, tem-se o acesso à justiça, direito fundamental garantido constitucionalmente, o qual também passa pelo direito à informação, pode-se observar que desde a linguagem até a forma na qual os processos são tratados em algumas cidades do interior, como na obra kafkaniana, isto é, de forma obscura, ambígua, ou até mesmo incitando o medo por está envolvido com "a justiça". Nesse sentido, tem-se os ensinamentos de Mauro Cappelletti:

O estudo era tipicamente formalista, dogmático e indiferente aos problemas reais [...]. Sua preocupação era frequentemente de mera exegese ou construção abstrata de sistemas e mesmo, quando ia além dela, seu método consistia em julgar as normas de procedimento à base de sua validade histórica e de sua operacionalidade em situações hipotéticas. [...]. Os estudiosos do direito, como o próprio sistema judiciário, encontravam-se afastados das preocupações reais da maioria da população (CAPPELLETTI, 1988, pp. 9-10).

Além desses obstáculos de cunho histórico dentro das vaidades do mundo jurídico, tem- se ainda um fator propulsor da descaracterização do acesso à justiça - a grande mídia; responsável pela propagação da informação na era pós-moderna, os meios de comunicação possuem um grande papel na repercussão dos casos judicializados, desde aqueles chamados de comoção popular, aos casos de corrupção e crimes políticos. dando a muitos deles "sua devida importância, bem como, o seu veredito". 
Assim, funcionando como longa manus do poder judiciário e amparada no direito à informação, a mídia acaba negligenciando outros princípios importantes do Direito como: presunção de inocência, previsto no artigo 5ํㅡ. LVII, o Devido Processo Legal, previsto no artigo 5ํㅡ, LIV, da Constituição Federal de 1988, além de violar o princípio da dignidade da pessoa humana alicerce do Estado Democrático de Direito.

Portanto, observa-se que em se tratando de direitos, o poder midiático estende sua influência cuja consequência é a desinformação, confusão ou omissão daquilo que realmente ocorre, uma vez que o propagado é seleto e relativizado de modo a desfuncionalizar os propósitos assegurados pelo Estado Democrático de Direito gerando insegurança jurídica sobre como proceder em cada caso a fim de que haja proteção aos direitos fundamentais e da Constituição. Dessa forma, percebe-se que o acesso à justiça resta prejudicado não só pelas próprias barreias burocráticas, mas também pela forma como é veiculado e utilizado - como meio para se chegar a um determinado fim - não necessariamente a justiça, como aduz Mauro Cappelletti:

Finalmente, como fator complicador dos esforços para atacar as barreiras ao acesso, deve-se enfatizar que esses obstáculos não podem simplesmente ser eliminados um por um. Muitos problemas de acesso estão inter-relacionados, e as mudanças tendentes a melhorar o acesso por um lado podem exacerbar barreiras em outro (CAPPELLETTI, 2002, p.11).

Nesse sentido, ocorre uma espetacularização de direitos, visto que é preferível acreditar nas imagens e depoimentos mostrados de forma a violar também os direitos daqueles que estão envolvidos como nos casos de programas passados em rede nacional aberta como - 'cidade alerta', ou nas redes digitais nas quais são veiculadas de forma escancarada o discurso de ódio ou a cultura do cancelamento, bem como a propagação da volta dos suplícios públicos, além da generalização dos casos e suas punições. Desse modo, preleciona Michel Foucault:

[...] o suplício faz parte de um ritual. Em relação a vítima, ele deve ser marcante: destina-se [...] ou pela ostentação de que se acompanha, a tornar infame aquele é sua vítima; o suplício, mesmo se tem como função "purgar" o crime, não reconcilia; traça em torno, ou melhor, sobre 
o próprio corpo do condenado sinais que não devem se apagar; as memórias dos homens, em todo caso, guardará a lembrança da exposição, da roda, da tortura ou do sofrimento devidamente constatados. E pelo lado da justiça que o impõe, suplício deve ser ostentoso, deve ser constado por todos, um pouco como seu triunfo (FOUCAULT, 1997, pp. 31-32).

Desse modo, ao analisar as facilidades tecnológicas e de acesso às informações prontas, houve uma disfuncionalização do estudo do direito passando a ser esquematizado e orientado no sentido de não ensinar o indivíduo a pensar de forma crítica, mas a simplesmente aplicar a norma ao caso, sem as complicações diárias de se observar que por trás daqueles processos existem pessoas. Assim, preleciona Lênio Streck:

Em nosso país, não há dúvida de que, sob a ótica do Estado Democrático de Direito - em que o Direito deve ser visto como instrumento de transformação social -, ocorre uma disfuncionalidade do Direito e das Instituições encarregadas de aplicar a lei (STRECK, 2011, p.43).

Dessa forma com a interferência midiática, o Estado Democrático Direito perde a sua essência de garantir a soberania popular, pois permite que o domínio de uma minoria controle os elementos necessários para a manipulação do povo, corrompendo seu intento em assegurar que injustiças não aconteçam, novamente, fundamentados pela legalidade.

Além disso, é possível citar outra falha nesse sistema que é o uso parcial da hermenêutica, no sentido de permitir que o judiciário faça interpretações dos casos concretos, de modo a beneficar determinado indivíduo ou grupo, em detrimento de outrem, desrespeitando regras de impedimento, ou suspeição exigidas pelo Direito, bem como, o não pré- julgamento e condenação por meio de juízos de valor, estas são heranças deixadas de uma divisão de classes em que uns podem fazer tudo, enquanto outros devem obedecer sem argumentar. Conforme aduz Boaventura de Sousa Santos:

Neste contexto, a concretização da revolução democrática da justiça passa a requerer uma dupla vigilância, política e pragmática. A vigilância 
política tem como pressuposto a consciência de que a legalidade cosmopolita ao combater a exclusão através do uso de ferramentas do sistema hegemônico corre o risco de ser cooptada por ele, legitimar o monopólio da legalidade hegemônica e, assim, afirmar o contrato social moderno e a exclusão por ele gerada. (SANTOS, 2011, p.109)

Assim, o que se pode depreender é que o Estado Democrático de Direito é uma conquista dentro do contexto não só da sua criação, como também na atualidade, visto que a partir do momento em que princípios ganham força de lei e as Constituições ganham supremacia, a ideia é de proteger, assegurar e valorizar o ser humano enquanto pessoa, garantindo-Ihe uma vida digna que engloba respeito aos seus direitos fundamentais. Conforme preleciona Sarlet:

[...] a dignidade possui também um sentido cultural, sendo fruto do trabalho de diversas gerações e da humanidade em seu todo, razão pela qual as dimensões natural e cultural da dignidade da pessoa se complementam e interagem mutuamente, refutando-se a tese de que a dimensão ontológica da dignidade possa ser equiparada a uma dimensão por assim dizer biológica ( SARLET, 2007, p. 47).

Nesse sentido, pode-se apontar que o resultado da insegurança jurídica, produz um conceito de impunidade que fomenta ainda mais a sensação de impotência daqueles que são dominados, visto que começam a enxergar o judiciário como um ‘órgão' no qual só é possível obter ganho de causa se for por meios escusos, ou quem precisa dele é porque de algum modo violou as normas.

\section{CONSIDERAÇÕES FINAIS}

O direito à memória faz parte da compreensão do princípio da dignidade da pessoa humana, uma vez que não é possível o entendimento de uma vida digna quando o indivíduo não consegue identificar-se através de suas memórias a qual grupo pertence e assim poder passá-las para as suas próximas gerações. Nesse sentido, a memória coletiva para ser construída de forma efetiva deve contar com a participação de todos, e isso só será viável, a partir do momento em que o acesso à informação - 
direito fundamental assegurado constitucionalmente - possa ser disponibilizado de forma democrática e menos tendenciosa.

No entanto, é possível perceber que o óbice dessa formação da memória encontra-se em sua maioria na concentração dos meios de comunicação por grandes empresários, os quais espetacularizam o direito à informação do cidadão reduzindo-o a uma função simplória de reprodução robótica. Assim, tem-se hoje, uma coletividade, em sua maioria, submissa e alienada, desejosa de pertencer aos padrões impostos de tal forma a sacrificar aquilo o que tem de mais valioso, sua identidade.

Nesse sentido, tem-se como consequência não só a deturpação do direito à memória e da informação, mas também do acesso à justiça e, principalmente, a relativização dos conceitos do Estado Democrático de Direito, visto que a mídia funciona como propulsora, ou produtora de opinião em todos os campos, resultando no desrespeito aos princípios constitucionais e promovendo uma sensação de insegurança jurídica.

Desse modo, uma das consequências dessa influência, é o crescimento do preconceito contra o Judiciário, além do endeusamento de figuras jurídicas, sem levar em conta de que forma está sendo conduzido o processo, visto que a educação jurídica não faz parte da grade de informações veiculadas pela mídia.

Além disso, aos meios de comunicação é reservado um papel de contribuir para a perpetuação do establishment, inclusive por meio de artimanhas ideológicas, reforçando a reprodução de discursos de ódio gerando parcialidade na reprodução das informações e das garantias fundamentais asseguradas pela Constituição Federal de 1988. Assim sendo, é possível observar também a influência midiática na manutenção dos padrões pré-estabelecidos, a saber, o distanciamento cultural entre a jurisdição acesso à justiça - e o povo.

Com essa compreensão percebe-se que a instrução não é um objetivo dos mercados comunicacionais, pois que o pensamento crítico faz com que a caverna da ignorância deixe de ser interessante e passa-se a questionar a importância da luz (conhecimento). Esse ensinamento platônico traduz a ideia de democratizar os meios de comunicação, visto que permite ao cidadão a possibilidade de visualizar mais de um 
feixe luz, isto é, mais de uma versão do mesmo fato e não aquela mais saudável à saúde do capital.

\section{REFERÊNCIAS}

BAUMAN. Zygmunt.Capitalismo parasitário e outros temas contemporâneos. Trad: Eliana Aguiar. 1를. Ed. Rio de Janeiro: Zahar, 2010.

. Modernidade Líquida. Trad. Plínio Dentzien.Rio de Janeiro: Zahar, 2001.

BOBBIO, Norberto. A Era dos Direitos. 1 Ed. 12. tir. Rio de Janeiro: Campus, 1992.

BONAVIDES, Paulo. Teoria Constitucional da Democracia Participativa. São Paulo:Malheiros, 2001.

BOURDIEU, Pierre. O Poder Simbólico. 11 Ed. Rio de Janeiro: Bertrand Brasil, 2007.

CAUDAU, Joel. Memória e Identidade. Trad. Maria Leticia Ferreira. São Paulo: Contexto,2011.

CAPPELLETTI, Mauro; GARTH, Bryant. Acesso à Justiça. Trad. Ellen Gracie Northfleet. Porto Alegre: Fabris, 1988.

CUNHA JÚNIOR, Dirley da. Curso de Direito Constitucional. 10 ed. Salvador: JusPodivm,2016

DEBORD, Guy. A Sociedade do Espetáculo: comentários sobre a sociedade do espetáculo.Trad. Railton Sousa Guedes. Rio de Janeiro: Contraponto,2003. E-book. Disponível em:< https://www.marxists.org/portugues/debord/1967/11/sociedade.pdf.> Acesso em: 03 Maio 2019.

FEUERBACH, Ludwig. A Essência do Cristianismo. Brasil: Vozes, 2009.

FOUCALT, Michel. Microfísica do Poder. 18 Ed.. Rio de janeiro: Graal, 2003. . Vigiar e Punir. 26 Ed.Petropólis: Vozes, 1997

HALBWACHS, Maurice. A Memória Coletiva. São Paulo: Centauro, 2003. 
SANTOS, Boaventura de Sousa. Para uma Revolução Democrática da Justiça. 3 ed. São Paulo: Cortez, 2011.

SARAIVA, Paulo Lopo. Constituição e Mídia no Brasil. São Paulo: MP, 2006.

SARLET. Ingo Wolfgang. Dignidade da Pessoa Humana e Direitos Fundamentais. 5 ed. Porto Alegre: Livraria do Advogado, 2007.

SCHREIBER, Anderson. (Org.). Direito e Mídia. São Paulo: Atlas, 2013.

STRECK, Lenio Luiz. Verdade e Consenso Constituição, Hermenêutica e Teorias Discursivas. 5 ed. São Paulo: Saraiva, 2014.

- Hermenêutica Jurídica $e(m)$ Crise uma Exploração Hermenêutica da Constituição do Direito. 10 ed. Porto Alegre: Livraria do Advogado, 2011. 